\title{
Awareness and Attitudes of Tennessee Consumers Towards Agricultural Biotechnology: Survey Results
}

\author{
Hiren Bhavsar ${ }^{1}$, Fisseha Tegegne ${ }^{1}$, Enefiok Ekanem ${ }^{1} \&$ Surendra P. Singh ${ }^{2}$ \\ ${ }^{1}$ Department of Agricultural and Environmental Sciences, Tennessee State University, Nashville, Tennessee, \\ United States \\ 2 Formerly Chair, Department of Agricultural and Environmental Sciences, Tennessee State University, \\ Nashville, Tennessee, United States \\ Correspondence: Hiren Bhavsar, Department of Agricultural and Environmental Sciences, Tennessee State \\ University, Nashville, Tennessee 37209, United States. Tel: 1-615-963-1498. E-mail: hbhavsar@tnstate.edu
}

Received: July 21, 2014 Accepted: November 20, 2014 Online Published: November 26, 2014

doi:10.5539/jfr.v4n1p97 URL: http://dx.doi.org/10.5539/jfr.v4n1p97

\begin{abstract}
The progress made in the field of biotechnology, also known as Genetic Engineering, over the years has made way for many new outcomes in different fields. However the immense potential of 2biotechnology has not convinced ordinary people to buy into Genetically Modified (GM) foods. A telephone survey conducted by a marketing firm, Advanced Strategic Research (ASR), was contracted to gather data from consumers in selected urban locations in Tennessee. The objective of this paper was to assess awareness and attitudes of Tennesseans towards agricultural biotechnology. The results showed that there is need for disseminating research based information to stakeholders as majority of those surveyed are not aware about agricultural biotechnology and do not have a favorable attitude towards it. Cooperative Extension programs in concert with others have major role to play in the education and information dissemination efforts.
\end{abstract}

Keywords: agricultural biotechnology, awareness, attitudes, telephone survey, consumers, Tennessee

\section{Introduction}

As per 'International Service for the Acquisition of Agri-biotech Applications (2014)', biotechnology has shown great progress over the last couple of decades in the agricultural sector in general and food sub-sector in particular. However, genetically modified (GM) foods remain a major source of controversy in many countries around the world. Since GM crops are the source of some of the most common ingredients used in food production, and because GM varieties of corn, soybeans and canola are often mixed with ordinary varieties, the incorporation of at least small amounts of GM ingredients in many processed foods is virtually inevitable. For example, many processed sweetened foods like sodas and baked goods often contain high-fructose corn syrup obtained from a silo storage system in which genetically modified corn is neither tracked nor treated differently than non-GM varieties. Currently, there is little diversity among available GM products; corn, soy, cottonseed and canola account for the bulk of GM ingredients in the food supply. Attempts by government, media and industry to inform the public about GM foods have gone largely unnoticed by most Americans (Hallman et al., 2003).

Attitudes and perceptions of consumers regarding agricultural biotechnology is mixed (Lang, 2013; Aleksejeva, 2013; McHughen, 2010). Agricultural biotechnology, has generated a lot of controversy worldwide (McHughen, 2010). Consumers are willing to buy biotech products if it has added nutritional benefits (Hossain, Onyango, Adelaja, Schilling, \& Hallman, 2003). The technology has the potential to change the nature of humanity (Simonneaux, 2000; Leislie \& Schibeci, 2003). However, limited outreach of important biotechnological research has led to frequent public opposition to its adoption (Brettell, 1999; Kirkpatrick et al., 2002). Increasing public awareness has been reported to tilt opinion towards favoring and adopting biotechnology (Aziz et al., 2009). Public exposure to genetic transformation in plants and animals as well as application relating to the environment is needed for the sustenance of the agricultural industry (Bagchi-Sen \& Scully, 2007; Falk et al., 2008; Wilson \& Flowers, 2002). Dissemination of information is also key for the future of biotechnology. A recent study of university student, an important consumer segment, shows that those with background in biological sciences have more favorable attitudes towards agricultural biotechnology than those in other 
disciplines (Tegegne et al., 2013). Extension professionals are found to be a trusted source of information for the consumers regarding GM foods (Ekanem et al., 2006).

\subsection{Objectives}

This paper presents the results of a survey examining the basis of what Tennesseans know about agricultural biotechnology and their attitudes towards it. In the beginning, Tennesseans' awareness of package labeling in general and their awareness of agricultural biotechnology on these labels in particular were examined. Furthermore, Tennesseans' opinions about a variety of existing agricultural food products affected by biotechnology were examined. Also, reactions to possible future products with direct and indirect consumer benefits were gauged. Finally, Tennesseans' actual and perceived knowledge of biotechnology and its use in food production and how these attitudes relate to opinions of agricultural biotechnology were explored. This paper focuses on Tennesseans' attention on agricultural biotechnology and lay the groundwork for programs that will increase consumer knowledge and awareness of agricultural biotechnology.

\section{Data and Methodology}

The data used in this paper is part of a larger set collected by Advanced Strategic Research (ASR) a private market research firm using telephone interviews of selected Tennessee consumers. The survey instrument was designed by a committee consisting of researchers at 1890 universities including Tennessee State University. ASR trained all personnel before the interviews to promote familiarity with the content of the survey. The survey required approximately eight minutes to complete. Supervisors scrutinized interviewers constantly using a sophisticated system which monitored audio activity.

\subsection{Sample Selection}

Non-institutionalized 199 adult consumers (18 years and older) with income per capita below the state average and 100 consumers with income per capita equal to the state average were selected. The 299 people were interviewed using random proportional probability dialing.

A random-digit-dialing sample frame was generated for the designated survey area which included listed and unlisted phone numbers. The computer system used a random selection procedure to select the initial set of potential survey participants. Sample representativeness was enhanced by using a call back system which made repeat calls to no answers at different times on different days.

Data was collected using the Computer Assisted Telephone Interview (CATI) software and online interviewing stations. Computerized data collection ensured proper implementation of automatic rotation and skip patterns, reducing potential survey error. The Project Supervisor monitored staff, supervisors and interviewers constantly paid special attention to technical details such as termination points, rotation and skip patterns. The 299 completed interviews yielded a sampling error rate of $\pm 3.4 \%$ at a $95 \%$ level of confidence.

\subsection{Sample Demographics}

Sample demographics involved gender, age, race, income and religious preference and is summarized in Table 1. The majority of respondents were female (78\%), which would indicate that primary decision maker regarding purchase of food products were women. Using standard U.S. Census categories, approximately $83 \%$ of the sample group identified themselves as being Caucasian, which is close to state average of $79 \%$. Almost $11 \%$ were African-American and $5 \%$ did not respond. Less than $1 \%$ of the sample were Asian, Hispanic, Native American or of Mixed Origin.

Figure 1 show that most respondents had completed high school and nearly half had some type of post-secondary education. Of these, $16 \%$ graduated from college and $6 \%$ had post-graduate education. 


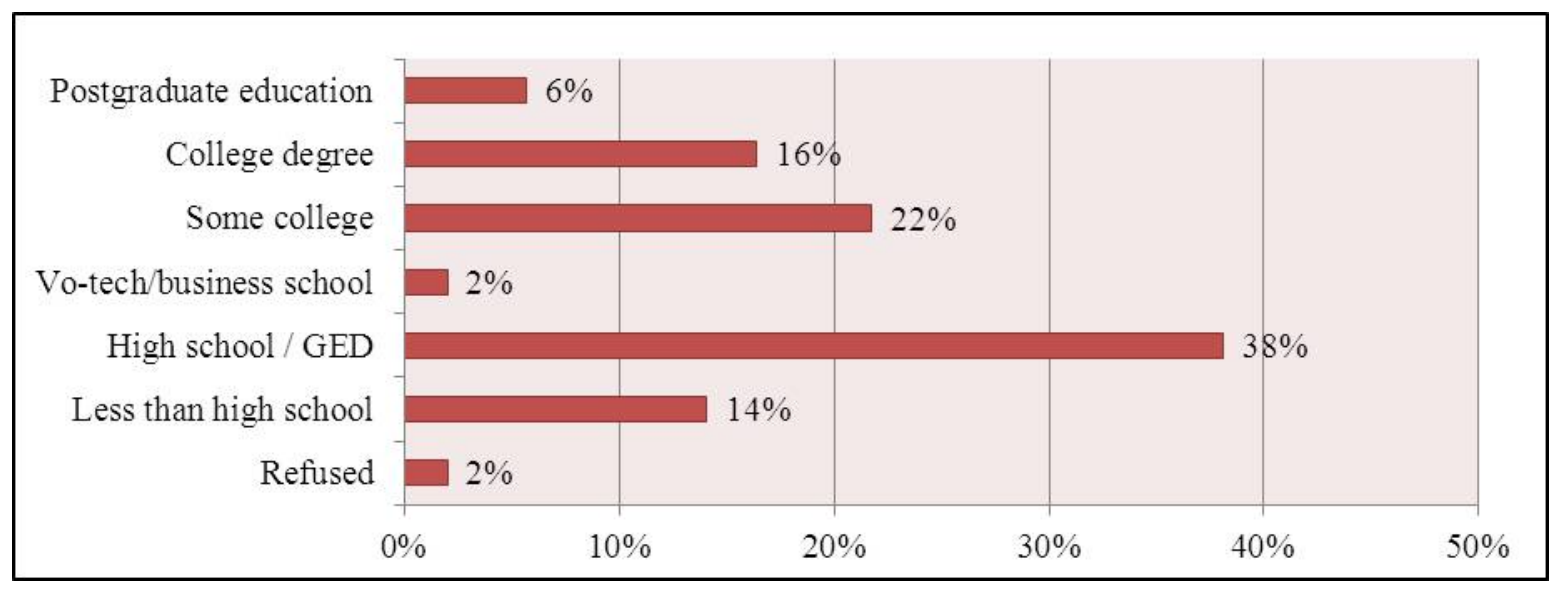

Figure 1. Education level of survey respondents in percentages

Figure 1 shows that the largest number of respondents (38\%) had a high school diploma or GED. $22 \%$ of the respondents had college degree or above with $6 \%$ of them having post-graduate education. A small number (2\%) preferred not to answer the question about their level of education.

On questions relating to income levels less than one quarter (24\%) had incomes above $\$ 50,000,52.8 \%$ had income below $\$ 50,000$ and nearly one quarter $(23 \%)$ refused to answer.

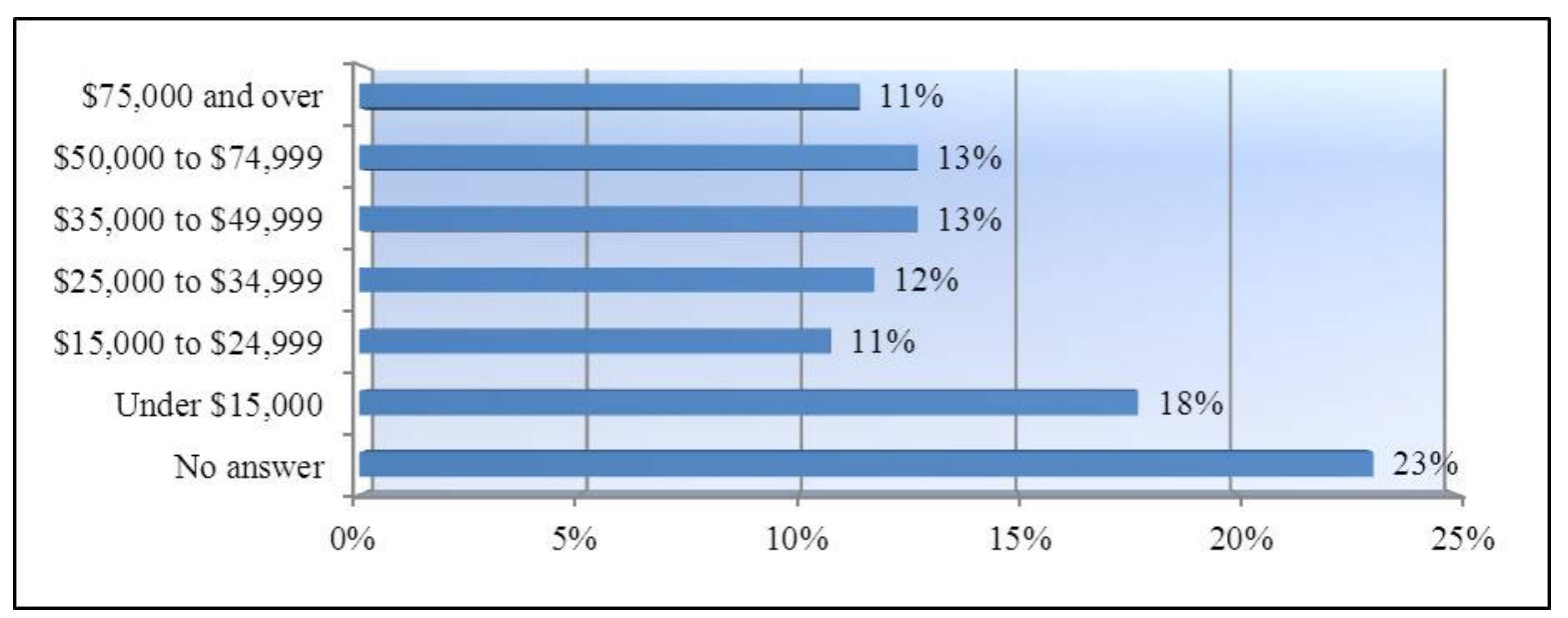

Figure 2. Annual household income of survey respondents

\section{Results}

While most Tennesseans consume or use products every day that have been modified by biotechnology, they know very little about it. As described below, few claim to have heard or read much about agricultural biotechnology, few are aware of the presence of ingredients in consumable goods or in their own diets, and few have ever discussed the topic with anyone else. However, Tennesseans are realistic in their assessment of their own personal knowledge of agricultural biotechnology; most report having little or no knowledge about it. Basic quizzes on biotechnology and product knowledge reveal that Tennesseans are generally uninformed about both as results presented below show.

\subsection{Knowledge and Awareness of Agricultural Biotechnology}

For the purpose of this study, knowledge of biotechnology can be described as information used by consumers in any format that has increased their understanding and awareness of agricultural biotechnology.

A summary of Tennesseans' knowledge of food labels is provided in Figure 3. On questions relating to basic knowledge of food labels, approximately $55 \%$ of the sample group indicated that they were knowledgeable about 
nutritional information on food labels, while $8 \%$ stated they never reviewed this information. About $37 \%$ had some or a little knowledge about food labels.

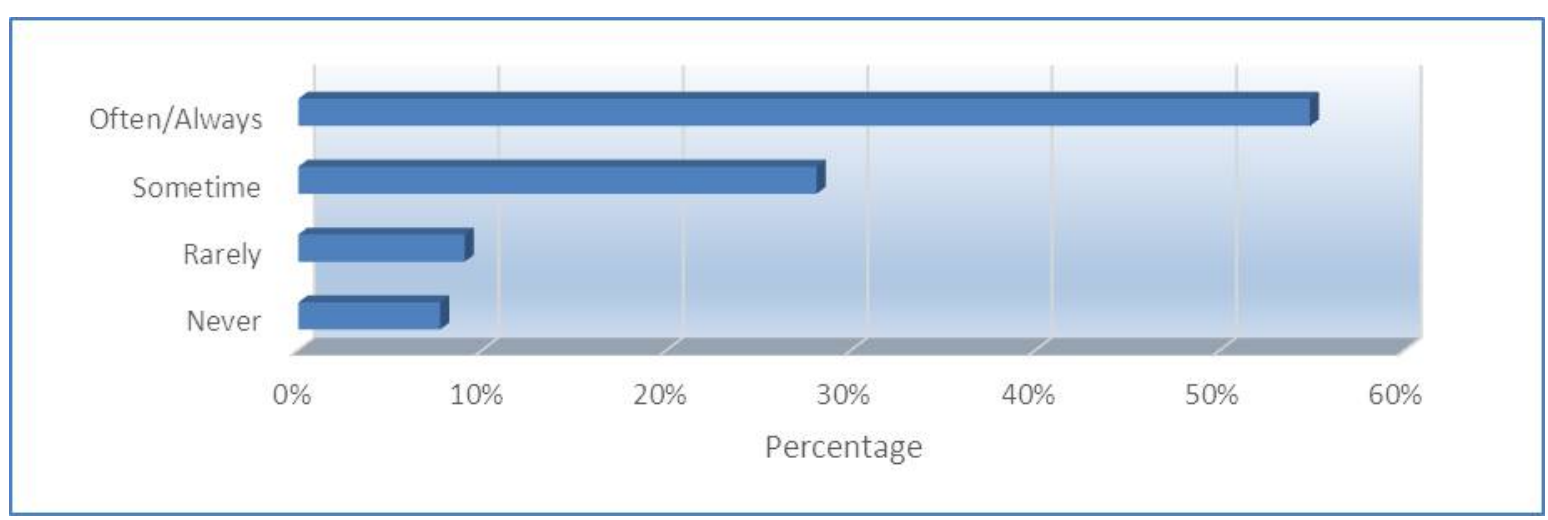

Figure 3. Consumers' knowledge of nutritional value based on frequency of reading food labels

Table 1 provides summary of information related to food labels and tendencies of Tennesseans on reading food labels. On questions relating to specific knowledge of food labels, approximately 61 percent of those surveyed said they often gathered information from the nutrition panel on food labels, while only $3 \%$ never reviewed this label panel. $28 \%$ had some or a little knowledge about nutritional information on food labels. These findings are in stark contrast to the findings of Tennesseans' knowledge of biotechnology information on food labels. Only $14 \%$ of those surveyed said they often read the biotechnology information from food labels, while $57 \%$ knew nothing about this information on food labels. Another $29 \%$ had some or a little knowledge about it.

Table 1. Summary of responses relating to reading food labels

\begin{tabular}{llllll}
\hline & $\begin{array}{l}\text { List of } \\
\text { Ingredients }\end{array}$ & Short Phrases & Nutrition panel & $\begin{array}{l}\text { Chemical } \\
\text { Information }\end{array}$ & $\begin{array}{l}\text { Biotechnology } \\
\text { Information }\end{array}$ \\
\hline Unsure & $8 \%$ & $8 \%$ & $8 \%$ & $10 \%$ & $14 \%$ \\
Never & $5 \%$ & $5 \%$ & $3 \%$ & $36 \%$ & $43 \%$ \\
Rarely & $6 \%$ & $10 \%$ & $8 \%$ & $16 \%$ & $15 \%$ \\
Sometime & $33 \%$ & $23 \%$ & $20 \%$ & $14 \%$ & $14 \%$ \\
Often/Always & $48 \%$ & $54 \%$ & $61 \%$ & $22 \%$ & $14 \%$ \\
\hline
\end{tabular}

A summary of biotechnology awareness is provided in Figure 4. On questions relating to knowledge of biotechnology, less than 116 people out of the sample group of 299 knew something about food biotechnology, while only 28 respondents (9percent) knew a lot on the subject.152 respondents (51\%) did not know anything about biotechnology. On the subject of genetic engineering 146 people of the sample group (49\%) had some knowledge and additional 28 people (11\%) claimed to know a lot. 116 respondents (39\%) said that they knew nothing about genetic engineering. 


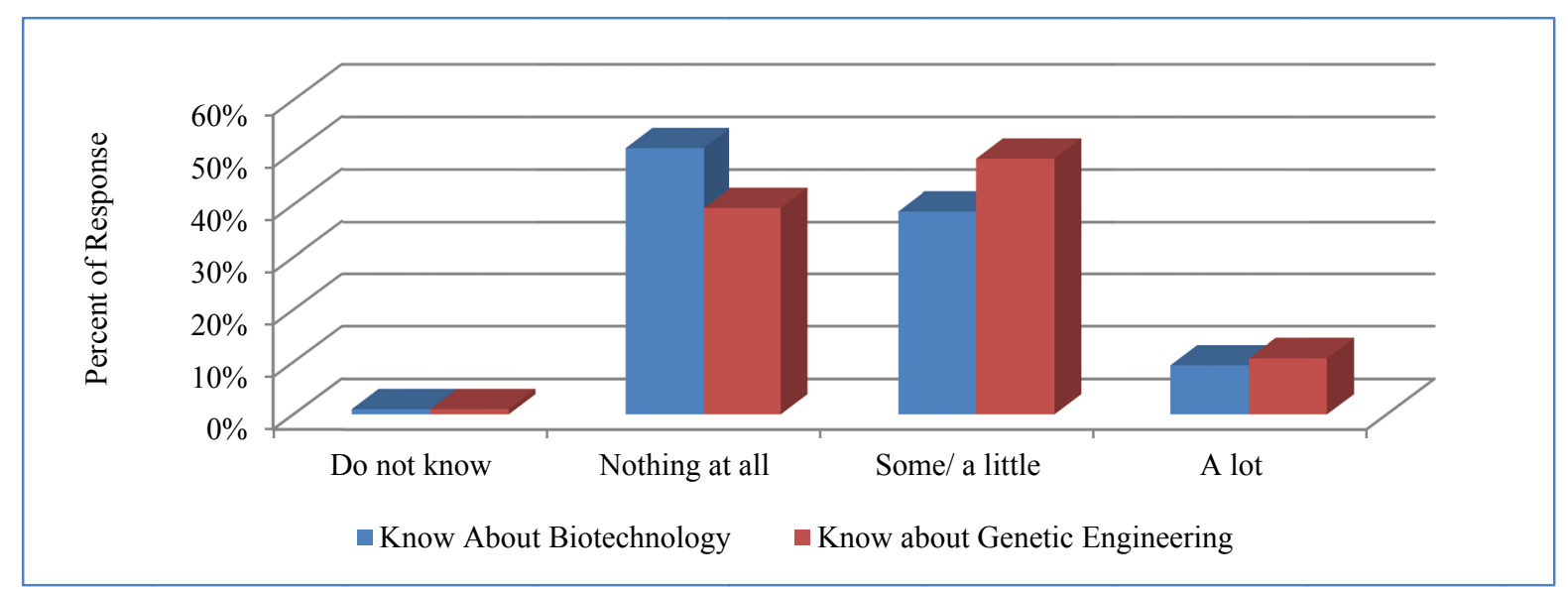

Figure 4. Awareness about agricultural biotechnology among respondents

\subsection{Attitudes towards Agricultural Biotechnology}

For the purpose of this study, attitudes toward agricultural biotechnology can be described as the individual survey participants' disposition, feelings, inclination, tendency, position, or views, either positive or negative, and form of biotechnology related to food or agriculture.

A summary of attitudes towards agricultural biotechnology and labeling are provided by Figures 5 and 6 , respectively. On questions relating to attitudes toward biotechnology, approximately $33 \%$ of the sample group knew nothing about biotechnology, while only $5 \%$ had a very positive opinion on the subject. About $25 \%$ were either neutral or preferred not to share their opinions about biotechnology. Approximately $20 \%$ had some type of negative point of view of biotechnology.

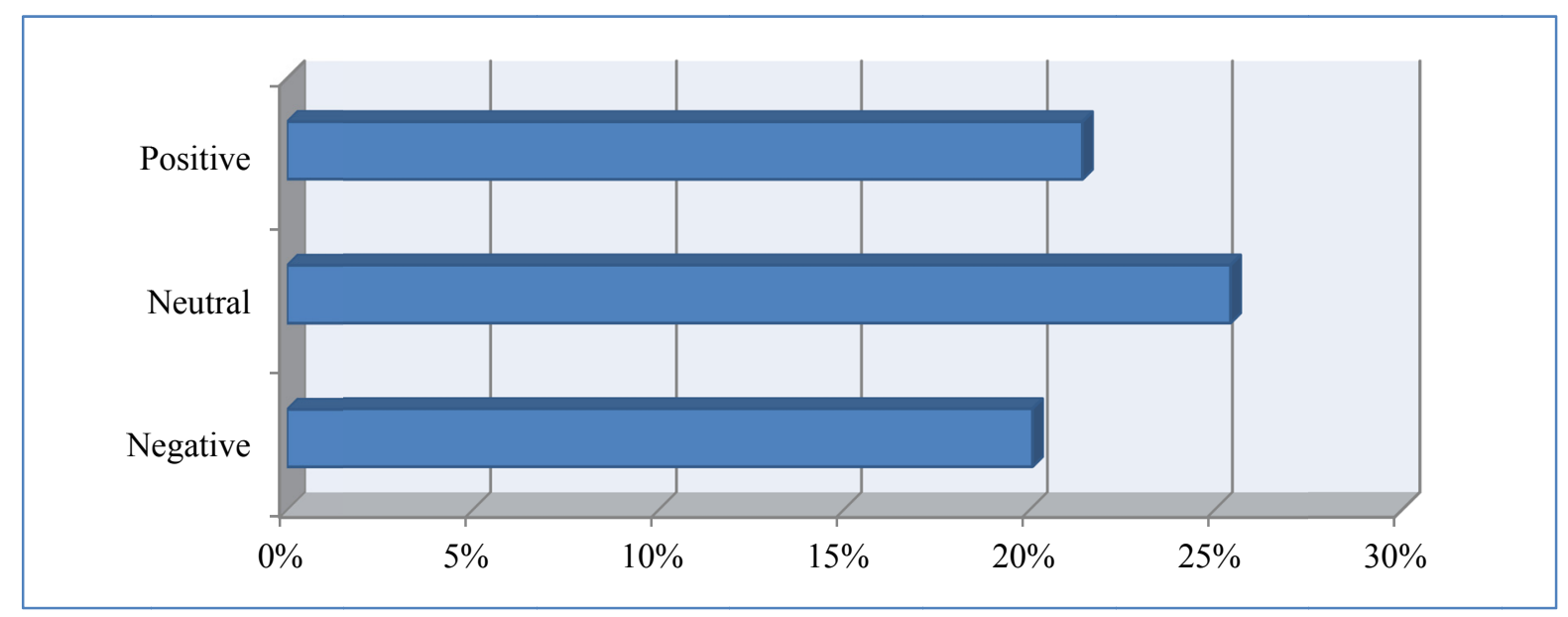

Figure 5. Consumers' attitudes towards agricultural biotechnology

Figure 6 shows the respondents' preferences regarding information on food labels. Overall, $60 \%$ of the respondents prefer to read the information regarding biotechnology on food labels. Only $7 \%$ of the respondents wanted biotechnology information on food labels when it changes nutrition values or contains some allergens etc. 
Food labels should indicate whether biotechnolgy is used or not

Biotechnology should be noted only when in introduces an allergen or changes food nutritional content

Unsure

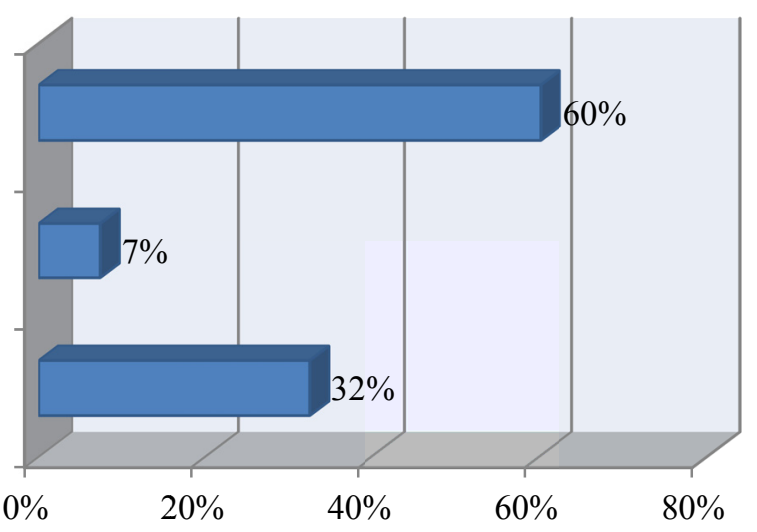

Figure 6. Tennesseans' attitudes towards food labeling involving biotechnology information

\subsection{Attitudes Influencing Purchasing Decisions}

For the purposes of this study, attitudes about agricultural biotechnology which influence food purchasing decisions can be described as any perception, idea, disposition, feeling, inclination, tendency, position, or view, either positive or negative, on any form of biotechnology related to food or agriculture products that might influence Tennessean's to pay either more or less for product that they would pay for at current prices.

Table 2. Consumers' willingness to pay (WTP) 20\% more for products with different attributes

\begin{tabular}{llll}
\hline & \multicolumn{2}{c}{ WTP 20\% More for } \\
\hline Very Likely & Organic & Non-Biotech & No Hydrogenated Fats \\
Somewhat Likely & $15 \%$ & $15 \%$ & $21 \%$ \\
Not Likely & $34 \%$ & $31 \%$ & $29 \%$ \\
Don't Know/Unsure & $19 \%$ & $19 \%$ & $16 \%$ \\
\hline
\end{tabular}

A summary of consumers' willingness to pay twenty $\%$ more for certain attributes is provided in Table 2. The table shows that $20 \%$ are not likely to pay twenty\% more for organic products. Nearly one out of three respondents was unsure. About $19 \%$ of the respondents were not likely to pay $20 \%$ more for organic, non-biotech or non-hydrogenated fats. Overall, $49 \%$ of the respondents are willing to pay $20 \%$ more for organic food. This shows a general attitude towards agricultural biotechnology product is not very positive. $32 \%$ were not sure about their preference to purchase organic food products.

Table 2 also shows that $46 \%$ of the respondents are somewhat or very likely to pay a higher price (20\% more) for non-biotech products. This shows small number of respondents are in favor of biotechnology. Consumers' willingness to pay twenty $\%$ higher price for non-hydrogenated fats has similar trends compared to non-biotechnology products. Only $16 \%$ of the respondents are against paying a higher price. Approximately half $(50 \%)$ of consumers are willing to pay $20 \%$ more for foods with non-hydrogenated fats. Thirty four $\%$ of the respondents were unsure about paying more.

\section{Discussion}

The results indicate that Tennesseans are generally unaware and not knowledgeable of agricultural biotechnology and its use in foods. While about half of Tennesseans were knowledgeable about food labels in general, only $14 \%$ actually read the biotechnology information on the labels and over half knew nothing about this information at all. Awareness of biotechnology was equally poor. Nearly $90 \%$ of Tennesseans had little or no awareness of agricultural biotechnology in food products.

Attitudes concerning the acceptability of using agricultural biotechnology in food products are relatively neutral. Over half of the public is unsure or neutral on the use of biotechnology in both plant-based and animal-based 
foods. These opinions were sensitive to how the question was worded. Tennesseans display more positive attitudes when the potential benefits of biotechnology, such as decreased use of pesticides, are mentioned.

While majority of the attitudes appear to be neutral, the impact these attitudes have on purchasing decisions is not. Nearly $50 \%$ of Tennesseans would be likely or somewhat likely to pay at least $20 \%$ more for products that have been certified non-agricultural biotechnology products.

Demographics and food choices somewhat influence acceptance of agricultural biotechnology. Women, respondents over 60 and those with low levels of education are somewhat less likely to approve of it than other groups. People who report that naturalness and healthfulness are important attributes of the food they choose, in addition to people who have a history of purchasing organic food, are less likely to approve of agricultural biotechnology. Most Tennesseans do not mention biotechnology when asked what information they currently see on food packaging, but nearly three-quarters of Tennesseans report that they believe the government should make labeling foods that contain agricultural biotechnology mandatory.

Most Tennesseans have yet to firmly make up their minds about agricultural biotechnology and how it should be used. These results are similar to those found by other studies (Onyango et al., 2003 \& Ferdaus et al., 2003). Until there is significant increase in Tennesseans' awareness and knowledge of agricultural biotechnology, it is unlikely that their attitudes will change. It is equally unlikely that Tennesseans will change their purchasing decisions at the supermarket.

Further research involving both social and natural sciences, is needed to determine the potential ramifications and impacts of increased knowledge and awareness of agricultural biotechnology will have on Tennesseans' health and economic condition. Dissemination of available agricultural biotechnology information would require concerted effort by different stakeholders, including extension agents, researchers and relevant government agencies. The information disseminated should be based on sound research. Further work on the subject should also examine policy parameters that impinge on consumers' attitudes towards agricultural biotechnology.

\section{Acknowledgements}

The authors would like to acknowledge the financial support provided by USDA - NIFA.

We also thank Drs. Ellene Kebede and Duncan Chambezi for their lead role in preparing the survey instrument.

We also acknowledge Dr. Benjamin Onyango, for providing input on the draft version of the paper.

Kofi Baryeh, Graduate Research Assistant, helped in literature search and his contribution is duly acknowledged.

\section{References}

Aziz, A. N., Tegegne, F., \& Wiemers, R. (2009). Benefits of Hands-On Biotechnology Training Workshops for Secondary School Educators and College Students. Journal of Biotech Research, 1, 72-79.

Bagchi-sen, S., \& Scully, J. (2007). Strategies and External Relationships of Small and Medium-sized Enterprises in the US Agricultural Biotechnology Sector. Environment \& Planning C: Government \& Policy, 25, 844-860. http://dx.doi.org/10.1068/c0560

Ekanem, E., Mafuyai-Ekanem, M., Tegegne, F., Muhammad, S., \& Singh, S. (2006). Consumer Trust in Extension as a Source of Biotech Food Information. Journal of Extension. Retrieved from http://www.joe.org/joe/2006february/rb2.php

Falk, H., Brill, G., \& Yarden, A. (2008). Teaching a Biotechnology Curriculum based on Adapted Primary Literature. International Journal of Science Education, 30(14), 1841-1866. http://dx.doi.org/10.1080/09500690701579553

Hallman, W. K., Hebden, W. C., Aquino, H. L., Cuite, C. L., \& Lang, J. T. (2003). Public Perceptions of Genetically Modified Foods: A National Study of American Knowledge and Opinion. (Publication number RR-1003-004). New Brunswick, New Jersey; Food Policy Institute, Cook College, Rutgers - The State University of New Jersey.

Hossain, F., Onyango, B. M., Adelaja, A. O., Schilling, B. J., \& Hallman, W. K. (2003). Nutritional Benefits And Consumer Willingness To Buy Genetically Modified Foods. Journal of Food Distribution Research, 34(1).

International Service for the Acquisition of Agri-Biotech Applications. (2014). Retrieved from http://www.isaaa.org 
Kirkpatrick, G., Orvis, K., \& Pittendrgh, B. (2002). Interactive learning: A Teaching Model for Biotechnology and Genomics Education. Journal of Biological Education, 37(1), 31-35. http://dx.doi.org/10.1080/00219266.2002.9655843

Leislie, G., \& Schibeci, R. (2003). What do science teachers think biotechnology is? Does it matter? Australian Science Teachers' Journal, 49, 16-21.

McHughen, A. (2010). Popular Misconceptions: Agricultural Biotechnology. New Biotechnology, 27(6), 724-728. http://dx.doi.org/10.1016/j.nbt.2010.03.006

Onyango, B., Hossain, F., Hallman, W., Schilling, B., \& Adelaja, A. (2003). Public Perception of Food Biotechnology: Uncovering Factors Driving Consumer Acceptance of Genetically Modified Food. Journal of Food Distribution Research, 34(1).

Simonneaux, L. (2000). Influence of Cultural and Disciplinary Identity on the Way Teachers in Agricultural Education in France Relate to Knowledge in Biotechnology. New Genetics and Society, 19, 23-48. http://dx.doi.org/10.1080/14636770050002946

Tegegne, F., Aziz, A. N., Bhavsar, H., \& Wiemers, R. (2013). Awareness of and Attitudes towards Biotechnology by Tennessee State University Students with Different Backgrounds and Majors. Journal of Biotech Research, 5, 16-23.

Wilson, E., \& Flowers, J. (2002). Secondary Educators' Confidence in Teaching Agricultural Biotechnology after Training. Journal of Natural Resources and Life Science Education, 31, 131-135.

\section{Copyrights}

Copyright for this article is retained by the author(s), with first publication rights granted to the journal.

This is an open-access article distributed under the terms and conditions of the Creative Commons Attribution license (http://creativecommons.org/licenses/by/3.0/). 